\title{
Perceções dos alunos da Licenciatura em Educação Básica sobre a sua formação
}

\author{
Adorinda Gonçalves*, Maria José Rodrigues* \\ * Escola Superior de Educação do Instituto Politécnico de Bragança
}

\begin{abstract}
Resumo
O objetivo do estudo é refletir sobre a formação dos futuros professores na Escola Superior de Educação de Bragança. Iniciou-se em 2011/2012 com a aplicação de um questionário a alunos da licenciatura e do $1 .^{\circ}$ ano dos mestrados, continuou com uma entrevista a uma amostra de quatro alunos do $3 .^{\circ}$ ano da licenciatura e o $3 .^{\circ}$ momento decorre, agora, aquando da conclusão do mestrado. Neste caso, reportamo-nos aos dados referentes à formação e à sua influência na Iniciação à Prática Profissional. Os resultados indicam que as práticas são reconhecidas como positivas, enriquecedoras e um contributo para o desenvolvimento profissional.

Palavras clave: Educação básica, Formação de professores, Iniciação à Prática Profissional
\end{abstract}

\section{Introdução}

Num mundo cada vez mais global é complexo o papel da Escola enquanto espaço de interação e de intervenção, cultural e social e é enorme a responsabilidade de professores e profissionais da educação.

Pensar a formação dos professores/educadores exige ter em conta a complexidade da escola e a multiplicidade de funções que têm de assumir os docentes, a quem se exige um amplo perfil de competências, “alguém a quem a sociedade confia a tarefa de criar contextos de desenvolvimento humano que envolvam o educando na multiplicidade de tarefas e interatividade das suas dimensões: cognitiva, afectiva, psicomotora, linguística, relacional, comunicacional, ética” (Alarcão \& Roldão, 2009, p. 16).

É neste sentido que a investigação, a troca de experiências, o debate de ideias e a reflexão sobre os processos de formação de professores e educadores são fundamentais.

É este, também, o sentido do estudo em curso na Escola Superior de Educação de Bragança, que tem vindo a acompanhar o percurso formativo dos alunos e tem fundamentado os reajustamentos necessários e possíveis, num quadro legislativo extremamente rígido. Este texto debruça-se sobre a perceção dos alunos da Licenciatura em Educação Básica e dos Mestrados em Ensino sequentes acerca da formação que estão a receber.

Trata-se de um estudo de natureza qualitativa, descritiva e interpretativa, desenvolvido em três fases. Iniciou-se no ano letivo 2011/2012 com a aplicação de um questionário a alunos de todos os anos da licenciatura e do $1 .^{\circ}$ ano dos mestrados, continuou com uma entrevista aplicada a uma amostra de quatro alunos do $3 .^{\circ}$ ano da licenciatura e está prevista a 3 . $^{\text {a }}$ fase de recolha de dados, após a conclusão do mestrado (junho de 2015).

Neste caso, reportamo-nos aos dados sobre a formação e a sua influência nas práticas de Iniciação à Prática Profissional (IPP). Os resultados indicaram um bom o grau de satisfação com a formação da licenciatura, embora fossem referidos aspetos que necessitavam de ser melhorados. No que concerne às práticas desenvolvidas em IPP, foram consideradas positivas, enriquecedoras e um contributo para o desenvolvimento profissional. A iniciação à prática profissional foi considerada um momento fundamental da formação, de confronto com a complexa realidade de ser professor, mas também a oportunidade para analisar os problemas e refletir para a sua resolução, para aplicar conhecimentos e desenvolver competências. Os alunos reconheceram a necessidade da formação ser ampliada ao nível do mestrado. Esperamos o balanço final, para perceber como evoluíram as percepções dos alunos e para refletirmos sobre aspetos que teremos de retificar para continuar a melhorar a formação de professores.

\section{Enquadramento}

A formação de professores é um processo complexo em que se joga a influência de múltiplos atores: Organizações, grupos sociais e culturais, sectores políticos e intelectuais. Daí resultam diferentes modelos de formação, que têm mudado ao longo do tempo. Apresenta-se uma análise do modelo de formação de educadores e de professores do ensino básico em Portugal e na Escola Superior de Educação de Bragança e o seu enquadramento em princípios teóricos.

Nóvoa (1991) considera dois grandes grupos de modelos de formação: "(i) os modelos estruturantes (tradicional, comportamentalista, universitário, escolar), organizados a partir de uma lógica de racionalidade científica e técnica, e aplicados aos diversos grupos de professores" (p. 21); (ii) os modelos construtivistas (personalista, investigativo, contratual, interativo reflexivo), que partem de uma reflexão contextualizada para a montagem dos dispositivos de formação contínua, no quadro de uma regulação permanente das práticas e dos processos de trabalho” (p. 21).

Esta é a visão mais aceite (Leitão e Alarcão, 2006 e Vieira, 2003) considerando-se a formação como um processo de desenvolvimento profissional a partir da atividade, da reflexão e da resolução de problemas. Os planos de formação devem ser flexíveis, inovadores e adaptados aos projetos e necessidades dos diferentes intervenientes, coerentes com os resultados da investigação devendo “a proposta de formação prática dos profissionais” (Formosinho, Oliveira-Formosinho \& Machado, 2010, p. 19).

Assim, a formação é concebida como um processo em espiral, em interação, com as crianças, entre pares e com profissionais, no qual se trocam pontos de vista e redescobrem conhecimentos e competências enfim, os alunos - futuros professores vão construindo 
continuamente competências pessoais e profissionais (Leitão e Alarcão, 2006).

\section{A formação de professores em Portugal}

Em Portugal, o Processo de Bolonha permitiu o desenvolvimento de novos planos de formação, profundamente influenciados por fatores políticos, que fixaram, por exemplo, a duração ou a estrutura da formação: licenciatura seguida de mestrado (Decreto-Lei n. ${ }^{\circ}$ 43/2007).

Esses planos privilegiam uma formação mais abrangente que permite uma melhor gestão dos recursos humanos e é concebida numa "perspectiva de desenvolvimento profissional”; reconhece a necessidade de formar um professor "capaz de adaptação do seu desempenho às mudanças decorrentes das transformações emergentes na sociedade, na escola e no papel do professor” , capaz de responder aos “desafios das situações singulares em função das especificidades dos alunos e dos contextos escolares e sociais" (Decreto-Lei n. ${ }^{\circ}$ 43/2007, p. 1321). Aponta-se, assim, para um modelo construtivista da formação.

À componente de formação educacional geral que "abrange os conhecimentos, capacidades, atitudes e competências no domínio da educação relevantes para o desempenho de todos os docentes”, incluindo a interação com "a comunidade e a participação na análise e no desenvolvimento de políticas educativas” (Decreto-Lei n. ${ }^{\circ} 43 / 2007$, artigo $14 .^{\circ},{ }^{\circ}{ }^{\circ}$ ) corresponde no máximo 20 ECTS, e as didáticas específicas (os conhecimentos, capacidades, atitudes e competências relativas ao ensino), tem um peso entre 15 e 20 ECTS na licenciatura mas é reforçada ao nível dos mestrados podendo atingir 35 ECTS (Decreto-Lei n. ${ }^{\circ}$ 43/2007, Artigo 16. ${ }^{\circ}$, n. ${ }^{\circ}$ 2).

A Iniciação à Prática Profissional (IPP) inclui “a observação e colaboração em situações de educação e ensino e a prática de ensino supervisionada" (Artigo 14. ${ }^{\circ}$, n. ${ }^{\circ} 4$, alínea a), é uma componente fundamental da formação, tem entre 15 e 20 ECTS na licenciatura e um peso muito importante nos mestrados, representado cerca de metade do tempo de formação. Esta organização dos planos curriculares indicia a valorização da prática profissional na construção de saberes, através da reflexão sobre situações e problemas emergentes dessa prática (Vieira, 2003; Cardona, 2006; Ponte, 2006).

Os planos contemplam a chamada "formação na área da docência” com 120 a 135 ECTS, assumindo que se exige o domínio dos conteúdos das disciplinas. Mas ao nível do $2 .^{\circ}$ ciclo, a ênfase dada aos conhecimentos específicos é praticamente insipiente, chegando a estar ausente nas formações de educadores de infância e professores do $1 .^{\circ}$ ciclo do ensino básico (Decreto-Lei n. ${ }^{\circ}$ 43/2007, Artigo $16 .^{\circ}$ ). Esta parece ser uma mensagem contraditória: na licenciatura deve assegurar-se toda uma bagagem de conhecimentos que os alunos-futuros educadores e professores virão a precisar em momento posterior da sua formação.

Após alguns anos de implementação do Processo de Bolonha, a análise e a reflexão sobre os processos desenvolvidos, a que não foi certamente alheia a avaliação externa dos cursos das diversas instituições, mostrou a necessidade de uma reformulação.
O novo modelo de formação foi aprovado pelo Decreto-Lei n. ${ }^{\circ}$ 79/2014. Reconhece-se o papel da formação de educadores e professores para a melhoria da qualidade da educação, o que leva a um reforço da formação nos Mestrados em Educação Pré-escolar e em Educação Pré-Escolar e Ensino do $1 .^{\circ}$ Ciclo e uma maior especialização ao nível do $2 .^{\circ}$ ciclo do ensino básico, passando a considerar-se duas vias: Ensino de Português, História e Geografia de Portugal no 2. ${ }^{\circ}$ ciclo; e Ensino da Matemática e Ciências Naturais no 2. ${ }^{\circ}$ ciclo.

Reforça-se a importância da formação na área da docência na licenciatura e, particularmente, nos mestrados, referindo-se que "as melhores práticas e o robusto conjunto de estudos internacionais (...) apontam consistentemente para a importância decisiva da formação inicial de professores e para a necessidade de essa formação ser muito exigente, em particular no conhecimento das matérias da área de docência" (Decreto-Lei n. ${ }^{\circ}$ 79/2014, p. 2819). Nesse sentido, na licenciatura passa para 125 ECTS, no mínimo, e é obrigatória em todos os mestrados (entre 6 ECTS e os 27 ECTS nos mestrados bivalentes) (Decreto-Lei n. $^{\circ}$ 79/2014, Artigos $13 .^{\circ}$ e $14 .^{\circ}$ )

Ao nível da iniciação à prática profissional, refere-se a importância de "a aprendizagem a realizar [ter] por base o conhecimento científico acumulado, o conhecimento profissional resultante da experiência” e se realizar "nas instituições de educação de infância ou nas escolas" que “(...) culmina com a prática de ensino supervisionada (...) concebida numa perspetiva de formação para a articulação entre o conhecimento e a forma de o transmitir" (Decreto-Lei n. ${ }^{\circ}$ 79/2014, Artigos $7^{\circ}$ e $11 .^{\circ}$ ).

Parecem assim, surgir, aspetos contraditórios: se por um lado se valoriza a análise crítica e a investigação educacional, como contributo para o desempenho das funções docentes em contextos complexos, pluridisciplinares, multiculturais e sociais, promotores do desenvolvimento, por outro lado, o Decreto-Lei citado apresenta indicadores que focam a formação de educadores e professores numa perspetiva aplicacionista e transmissiva.

\section{A formação de professores na Escola Superior de Educação de Bragança}

Na Escola Superior de Educação de Bragança têm funcionado a Licenciatura em Educação Básica aprovada pela Portaria n. ${ }^{\circ}$ 1618/2007, de 24 de dezembro, alterada pelo Despacho n. ${ }^{\circ} 4549 / 2013$, de 21 de março, e os Mestrados em Educação Pré-escolar, em Ensino do $1 .^{\circ}$ Ciclo, em Educação Pré-Escolar e Ensino do $1 .^{\circ}$ Ciclo, e em Ensino do $1 .^{\circ}$ e do $2 .^{\circ}$ Ciclo do Ensino Básico, desde 2007.

Analisam-se, de seguida, as formações da licenciatura, enquadradas pelo Decreto-Lei n. ${ }^{\circ}$ 43/2007, alvo das primeiras fases deste estudo.

O plano de estudos inicial da licenciatura contemplava duas unidades curriculares dedicadas à iniciação à prática profissional correspondentes a 15 ECTS. A alteração desse plano (Despacho n. ${ }^{\circ}$ 4549/2013), uniu essas unidades, mantendo o número de ECTS. Em qualquer dos casos, procurava-se envolver os alunos nos diversos contextos de educação pré-escolar e ensino básico (1. ${ }^{\circ}$ e 
2. ${ }^{\circ}$ ciclos), e relatar e problematizar as experiências com o apoio de instrumentos de observação e refletidas com base na literatura. Procurava-se, assim ir ao encontro das reflexões de Cardona (2006) e Ponte (2006), que apontam a importância do contacto com a prática profissional para o desenvolvimento do significado dos saberes trabalhados na formação, para o formando ir construindo as suas ideias, interpretar as situações e encontrar alternativas de intervenção para situações futuras.

O plano incluía a formação na área das TIC's, Psicologia da Educação e Sistema Educativo e Organização Curricular e ainda Ética, Educação e Cidadania e Metodologias de Investigação em Educação. Cada uma destas duas unidades tinha uma carga de 4 ECTS, o que pode ser entendido como uma limitação face à descrição das finalidades que lhes são atribuídas, que poderia ser suprida por uma cuidadosa articulação com a área de Iniciação à Prática Profissional em que os alunos deviam analisar e refletir sobre as situações e enquadrá-las do ponto de vista de referências e investigações atuais.

A formação nas didáticas específicas de Língua Portuguesa, de Matemática, de Estudo do Meio e das Expressões, correspondiam, no conjunto, a 20 ECTS e à componente de formação na área da docência correspondiam 120 ECTS, o valor mínimo permitido pelo Decreto-Lei.

Como foi referido, é a formação resultante deste currículo que foi objeto de análise na $1 .^{\mathrm{a}}$ e na $2 .^{\mathrm{a}}$ fase do estudo a que se refere este texto.

No que diz respeito aos mestrados em funcionamento na ESEB, os planos de estudos previam uma formação de 60 ECTS para o Mestrado em Educação Pré-escolar, 90 ECTS para o Mestrado em Educação Pré-escolar e Ensino do $1 .^{\circ}$ ciclo do Ensino Básico, e 120 ECTS para o Mestrado em Ensino do $1 .^{\circ}$ e do 2. ${ }^{\circ}$ ciclo do Ensino Básico. Apenas neste último caso, o plano previa um reforço da formação na área da docência com um peso significativo e nas áreas de Português, Matemática, Ciências Naturais e História e Geografia de Portugal, com 31 ECTS. Nos outros casos, a formação nesta área era incipiente, estava remetida a unidades curriculares optativas, ou não existia.

A área de formação dominante nestes planos era a iniciação à prática profissional que chegava a ultrapassar metade da carga horária do plano. Considerava-se, assim, como uma área central da formação para a qual deviam convergir as restantes. Como se podia assumir essa centralidade? Pode considerar-se que as atividades integradas na componente de iniciação à prática profissional, visavam possibilitar aos alunos a integração e sistematização de saberes, incentivá-los a observar, analisar e interpretar as práticas educativas e a implicar-se na procura de respostas para as questões e dificuldades com que se defrontavam. Estávamos, assim, a ir ao encontro das reflexões de Vieira (2003), Cardona (2006) e Ponte (2006) valorizando a prática profissional para a construção de saberes, através da reflexão sobre situações e problemas emergentes dessa prática.

Efetivamente, a prática de ensino supervisionada previa, além do estágio no(s) contexto(s) específico(s) para que o mestrado habilita, em que o aluno desenvolvia "um projeto curricular de ensino implementado nesse nível de ensino (...) que resulta da aplicação prática dos conhecimentos adquiridos (...) e da busca de inovação nas práticas pedagógicas”, a produção de um Relatório Final "objeto de ato público de defesa, (...) e [que deve] refletir o percurso de formação seguido, a atitude crítica e reflexiva em relação aos desafios, processos e desempenhos do quotidiano profissional experienciado" (IPB, sd, RPES, Artigo $3 .^{\circ}$ ), sustentada na literatura científica, pedagógica e investigativa de referência (IPB, sd, RPES, Artigo 8. ${ }^{\circ}$ ).

É sobre estes planos de estudos dos mestrados que incide a 3. ${ }^{a}$ fase da investigação.

Entretanto, estes planos foram retificados, alguns reajustamentos estiveram em vigor no ano letivo 2013/1014, mas não abrangeram os alunos já em fase final da sua formação, pelo que não estão incluídos na investigação em curso. No próximo ano letivo, entrarão em vigor os novos planos curriculares, de acordo com a nova legislação, Decreto-Lei n. ${ }^{\circ}$ 79/2014.

\section{Método}

O estudo carateriza-se por uma metodologia, essencialmente, qualitativa, de natureza descritiva e interpretativa. Desenvolveu-se em três fases; na primeira fase do estudo descrevemos o grau de satisfação dos alunos da Escola Superior de Educação de Bragança relativamente à formação na licenciatura em educação Básica e na segunda pretendeu-se conhecer a perceção de 4 alunas do $3 .^{\circ}$ ano da LEB, sobre a formação recebida e a sua influência nas práticas desenvolvidas no âmbito da Unidade Curricular de Iniciação à Prática Profissional. Na 3. ${ }^{a}$ fase, ainda em curso, proceder-se-á ao processo de recolha de dados por entrevista e por questionário, após a conclusão da formação. De acordo com Carmo e Ferreira (1998) na investigação em educação, os métodos qualitativos e quantitativos podem ser utilizados como complementares.

\section{Participantes}

$\mathrm{Na} 1 .^{\mathrm{a}}$ fase do estudo foram abrangidos os alunos da Licenciatura e os alunos do $1 .^{\circ}$ ano dos Mestrados sequentes em funcionamento na ESE de Bragança no ano letivo 2011/2012, uma população total de 263 alunos.

$\mathrm{Na} 2 .^{\text {a }}$ fase do estudo recorreu-se a uma entrevista semiestruturada, realizada em junho de 2013, individualmente, a quatro alunas do $3 .^{\circ}$ ano que tinham realizado experiências educativas nos diferentes contextos de Iniciação à Prática Profissional e que se voluntariaram para colaborar. Tratou-se, pois de uma amostra de conveniência.

$\mathrm{Na} \mathrm{3.}{ }^{\mathrm{a}}$ fase recorrer-se-á novamente a entrevistas semiestruturadas, às mesmas alunas já envolvidas no estudo, e a um novo questionário aplicado a alunos que concluíram os mestrados.

\section{Instrumentos e Materiais}

$\mathrm{Na} 1 .^{\mathrm{a}}$ fase do estudo recorreu-se a uma metodologia com caraterísticas quantitativas, assente no tratamento estatístico dos dados obtidos através de um inquérito por questionário, uma vez que estava envolvido um número 
significativo de alunos pelo que este instrumento seria o mais útil, rápido e económico (Muñoz, 2003) e permitia a obtenção de dados padronizados e generalizáveis (Sousa, 2005).

O questionário foi construído atendendo aos princípios enumerados por Foddy (2002), formulando-se questões breves, claras e objetivas. Inicia-se com um texto informativo, a finalidade e utilização da informação recolhida, e, ainda, a garantia do anonimato. O corpo tem em duas seções: (1) caraterização pessoal dos inquiridos; (2) grau de satisfação com o curso de LEB. O questionário é constituído por questões fechadas, de fácil resposta e posterior tratamento, e apenas três questões abertas, para que os inquiridos manifestassem a sua opinião livremente acerca dos aspetos mais e menos valorizados, e pudessem apontar algumas sugestões que pudessem melhorar a sua formação.

$\mathrm{Na}$ segunda fase do estudo recorreu-se a entrevistas semiestruturadas, a alunas do $3 .^{\circ}$ ano que tinham realizado experiências educativas nos diferentes contextos. Para o efeito foi elaborado um guião, definindo o âmbito sobre o qual incidiam as questões que permitiriam recolher informação sobre as opiniões, significados e acontecimentos ocorridos num determinado meio e para ter a certeza de se obter dados comparáveis entre vários sujeitos.

Desenvolveu-se a entrevista, permitindo que o entrevistado enriquecesse e expressasse mais facilmente a sua opinião e prevendo a explicitação ou a sua reformulação de algumas questões para atender às necessidades do entrevistado (Morgan e Guevara, 2008).

$\mathrm{Na} 3{ }^{a}$ fase do estudo recorrer-se-á novamente a entrevistas semiestruturadas, e a um novo questionário. Os processos de recolha de dados ainda estão em curso para posterior análise.

\section{Procedimento}

Considerando as diversas fases do estudo e de metodologias utilizadas, os procedimentos foram variando.

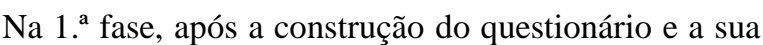
validação, de modo a garantir a credibilidade do estudo e a diminuir os erros, realizou-se a sua aplicação. Previamente, foi pedida autorização específica aos responsáveis da instituição e aos docentes dessas aulas. A aplicação foi feita pelas investigadoras que referiram os objetivos do estudo e do questionário e garantiram as condições de anonimato das respostas. Os questionários foram distribuídos a todos os alunos presentes nessas aulas, obtendo-se uma taxa de resposta de 60,2\%. Posteriormente, procedeu-se ao tratamento estatístico dos dados e, nas questões de resposta aberta, à análise de conteúdo, criando-se categorias de respostas à posteriori.

$\mathrm{Na}$ administração da entrevista, seguindo o guião estabelecido, teve-se em consideração três momentos distintos: (i) justificação do propósito da entrevista, destacando a importância da colaboração das entrevistadas para o desenvolvimento da investigação; (ii) desenvolvimento da entrevista de acordo com o guião previamente elaborado; e (iii) agradecimento da participação e reforço do pedido de disponibilidade para posteriores colaborações.
As entrevistas realizadas foram gravadas em registo áudio, posteriormente transcritas e sujeitas a análise de conteúdo.

\section{Resultados e discussão}

Relativamente à caraterização dos participantes, verificou-se que a maioria dos alunos que frequentavam a LEB e os mestrados profissionalizantes para a educação de infância e $10^{\circ}$ e $2 .^{\circ}$ ciclo do Ensino Básico eram do sexo feminino (87,8\%); tinham idades compreendidas entre 18 e 35 anos, sendo que a maioria entre os 21 e os 23 anos. Apenas quatro alunos eram estudantes trabalhadores.

Relativamente à organização e funcionamento do curso todos os itens tiveram uma avaliação positiva, predominando as respostas classificadas com satisfaz. No que diz respeito à avaliação global a maioria das suas respostas situava-se no nível 3 (satisfaz), mas salienta-se que uma tendência para respostas de nível mais elevado (satisfaz bem) com 32\%. Nos itens referentes ao "apoio dos professores" e à sua "preparação científica e pedagógica” os alunos mostraram um grau de satisfação elevado, com o maior número de respostas no nível 4 (satisfaz bem), resultados que foram reiterados nas entrevistas: "A formação oferecida é muito boa. Pela atitude dos professores para connosco, pela disponibilidade, estarem sempre dispostos para nos ajudar e para nos orientar (aluna A); Bom. Muito bom quer ao nível das unidades curriculares (...)ao nível do acompanhamento do corpo docente, da turma, há um espírito cooperativo e académico que é muito produtivo e que ajudou na integração e nessa satisfação (aluna B); Bom, é assim é bom porque deram-nos informações e sempre que nós tínhamos dúvidas (...) havia sempre um apoio (aluna D)".

De destacar os itens "relação entre a componente teórica e a componente prática” e "adequação da carga horária de IPP” como os que tiveram maior número de respostas "satisfaz pouco" e "não satisfaz”. Os alunos consideraram a prática como espaço de articulação e núcleo central da sua formação e revelaram desconhecimento das limitações legais da estrutura curricular ao proporem alterações do plano de estudos no sentido de um reforço da IPP. Este aspeto já tinha sido alvo de reflexão interna na instituição e conduzido às alterações curricularesmas muitos dos respondentes (nomeadamente os alunos dos mestrados e do 3..$^{\circ}$ ano da LEB em 2011/2012) tinham vivido o currículo anterior.

No mesmo sentido, os alunos referiram, um maior número de horas dedicado à IPP. Sugeriram, ainda, mudanças ao plano de estudos e alterações na carga horária por semestre e por unidade curricular, como evidenciam os seguintes episódios registados nas entrevistas: "haver uma melhor preparação para a prática em termos didáticos, conteúdos trabalhamos (...) como é que reagimos a diversos comportamentos, (...) devíamos ter um pouco dessa preparação para nos adequarmos mais ao contexto (aluna D); O tempo das unidades das ciências ser maior (...)às vezes as coisas são tão importantes (...) E temos outro tempo noutras unidades que eu acho que até é demasiado (aluna C); era 
importante $(. .$.$) nós tivemos as primeiras experiências$ (...) no entanto, (...) provavelmente não abordamos tudo que seria possível (aluna B)".

Globalmente, os alunos consideraram que a licenciatura os prepara para a intervenção nos diferentes contextos: "Sim, sem dúvida, aliás grande parte das intervenções foram planificadas em contexto de aula aqui, nas várias unidades curriculares, praticamente, salvo raras exceções, nós conseguimos em todas as áreas aplicar aquilo que trabalhado nas aulas (aluna B)".

Em síntese, a perceção dos alunos relativamente à organização e funcionamento do curso indicou que valorizam o trabalho que tem sido feito na instituição mas também que era necessário proceder a algumas alterações.

\section{Considerações Finais}

A formação de educadores/professores exige que as instituições de formação discutam e partilhem as experiências e se ouçam todos os agentes da formação. O processo de formação inicial é bastante complexo, tem de responder às exigências de múltiplos setores sociais e políticos e integrar diferentes perspetivas da escola e do sistema educativo. Por isso, é fundamental uma prática reflexiva que permita construir e reconstruir opções, expectativas e superar as dificuldades encontradas.

Um dos aspetos que importa salientar foi a necessidade de uma informação/consciencialização para o novo modelo de formação, no sentido de clarificar que a Licenciatura em Educação Básica não é um curso profissionalizante, e portanto, a Iniciação à Prática Profissional não é um estágio em que os alunos devam assumir uma postura profissional. Essa clarificação ajudaria os alunos a perceber a dispersão pelos diferentes contextos da educação básica e a reconhecer que a licenciatura alarga o leque de possibilidades de saídas profissionais. Esse é um esforço que se continua a fazer na instituição.

Entre os aspetos positivos que os alunos referiram, destacou-se a qualidade da formação nas suas diversas vertentes e a apreciação do trabalho dos professores. A apresentação deste projeto mostra, também, o empenhamento na procura constante de respostas para os problemas com que somos confrontados quotidianamente.

\section{Referencias}

Alarcão, I. \& Roldão, M. C. (2009). Supervisão - Um contexto de desenvolvimento profissional dos professores. Mangualde: Edições Pedagogo.

Cardona, M. J. (2006). Educação de infância - Formação e desenvolvimento profissional. Análise da Acção Educativa. Chamusca: Edições Cosmos.

Decreto-Lei n. ${ }^{0}$ 43/2007 de 22 de fevereiro - aprova o regime jurídico da habilitação profissional para a docência na educação pré-escolar e nos ensinos básico e secundário.

Decreto-Lei n. ${ }^{\circ}$ 79/2014 de 14 de maio - aprova o [novo] regime jurídico da habilitação profissional para a docência na educação pré-escolar e nos ensinos básico e secundário.
Despacho n. ${ }^{\circ}$ 4549/2013, de 21 de março - aprova a retificação ao plano de estudos do curso de Licenciatura em Educação Básica da escola Superior de Educação de Bragança.

Foddy, W. (2002). Como Perguntar - Teoria e prática da construção de perguntas em entrevistas e questionários. Oeiras: Celta Editora.

Formosinho, J., Oliveira-Formosinho, J. \& Machado, J. (2010). Docência, interacção pessoal e desenvolvimento humano. In J. Formosinho, J. Machado \& J. Oliveira-Formosinho (Orgs.), Formação, desempenho e avaliação de professores (pp. 11-24). Mangualde: Edições Pedagogo.

Leitão, A. \& Alarcão, I. (2006).Para uma nova cultura profissional: uma abordagem da complexidade na formação inicial de professores do $1^{\circ}$ CEB. Revista Portuguesa de Educação, 19 (2), 51-84.

Morgan, D. L. \& Guevara H. (2008). Interview Guide. The Sage Encyclopedia of Qualitative Research Methods. 2008. London: SAGE Publications.

Munõz, T. (2003). El cuestionário como instrumento de investigación/evaluación. Espanha: Almenjandrelo.

Nóvoa, A. (1991). Concepções e práticas de formação contínua de professores. In J. Tavares (Org.), Formação contínua de professores: Realidades e perspectivas (pp. 15-38). Aveiro: Universidade de Aveiro.

Ponte, J. P. (2006). Os desafios do processo de Bolonha para a formação inicial de professores. Revista da educação, 14(1), 19-36.

Portaria n. ${ }^{\circ}$ 1618/2007, de 24 de dezembro - aprova o plano de estudos do curso de Licenciatura em Educação Básica da escola Superior de Educação de Bragança.

Sousa, A. B. (2005). Investigação em Educação. Lisboa: Livros Horizonte.

Vieira, R. M. (2003). Formação Continuada de Professores do $1 .^{\circ}$ e $2 .^{\circ}$ Ciclos do Ensino Básico para uma Educação em Ciências com Orientação CTS/PC. Tese de Doutoramento não publicada. Aveiro: Universidade de Aveiro, DDTE. 